\title{
EVALUASI PENERAPAN AKUNTANSI PIUTANG LEASING DAN PELAPORANNYA PADA PT. ASTRA SEDAYA FINANCE DI MANADO
}

\author{
Erill Armando Tulangow ${ }^{1}$, Inggriani Elim² ${ }^{2}$ Rudy J. Pusung ${ }^{3}$ \\ 1,2,3 Jurusan Akuntansi, Fakultas Ekonomi dan Bisnis, Universitas Sam Ratulangi, Jl. Kampus Bahu, Manado, \\ 95115, Indonesia \\ E-mail : erillarmando@gmail.com
}

\begin{abstract}
The emergence of leasing institutions is an attractive alternative for entrepreneurs, because currently they use cash in cash for the company's operational activities. Through the lease they can generate funds to finance the purchase of goods with a term between three years to five years or more. The object of this research is PT. Astra Sedaya Finance Manado which is the largest automotive financing company in Indonesia. The purpose of this study is to analyze the accountability of Astra Sedaya Finance in Manado. The method used with descriptive method, with data data being used with. Which will be leased, the system of recording and reporting of leasing transactions evaluate the advantages / disadvantages of the application of accounting for lease transactions and reporting of lease transactions, and draw conclusions. The results can be seen that leasing has several types and classification and criteria to determine the accounting system. The application of accounting and reporting for lease transactions at PT Astra Sedaya Finance uses a system capital lease whereby the lease may transfer ownership at the end of the lease term. Based on aspects of Recording, reporting and disclosure, the accounting treatment of leases at PT Astra Seaya Finance is in conformity with the applicable PSAK.
\end{abstract}

Keywords : Leasing, Leasing Receivable Accounting, PSAK No.30

\section{PENDAHULUAN}

Seiring perkembangan zaman, pembangunan di setiap negara pun sangat pesat. Hal ini dilihat dari tingkat perkembangan iptek, sosial, dan politik. Semua negara didunia berlomba untuk menggunakan segala kemampuan dan ilmu pengetahuan yang mereka miliki untuk penyesuaian terhadap perkembangan tersebut. Demikian pula dalam rangka menunjang program pembangunan nasional, maka berbagai lembaga pemerintahan maupun swasta turut berperan serta dalam berbagai usaha demi menunjang keberhasilan pembangunan bangsa. Sehingga dengan semakin membaiknya pembangunan bangsa, perekonomian Indonesia pun ikut membaik. Tujuan perusahaan pada umumnya ialah untuk memuaskan kebutuhan dari konsumen dengan nilai-nilai tertentu. Tujuan perusahaan dapat digolongkan sebagai berikut :

a. Tujuan Pelayanan Primer

Tujuan primer adalah pembuatan barang/jasa yang dijual untuk memenuhi kebutuhan konsumen. Tujuan Organisatoris adalah nilai- nilai yang harus disumbangkan oleh masing-masing atau kelompok individu yang berada pada bagian yang bersangkutan. Tujuan Operasional adalah nilai-nilai yang disumbangkan oleh masing-masing tahap dalam suatu unit prosedur kerja secara keseluruhan.

b. Tujuan Pelayanan Kolateral

Tujuan Kolateral Pribadi adalah nilai-nilai yang ingin dicapai oleh individu atau kelompok individu dalam perusahaan. Tujuan Kolateral Sosial ialah nilai-nilai ekonomi yang lebih luas/umum yang diperlukan bagi kesejahteraan masyarakat dan yang dapat secara langsung dihasilkan dari kegiatan perusahaan. Tujuan Kolateral Sosial bersifat lebih luas untuk kepentingan masyarakat, misalkan : membayar pajak. 
c. Tujuan Pelayanan Sekunder

Merupakan nilai-nilai yang diperlukan oleh perusahaan untuk mencapai tujuan primer. Namun secara umum, tujuan perusahaan dapat berupa : (a) mencapai keuntungan maksimal; (b) mempertahankan kelangsungan hidup; (c) mengejar pertumbuhan; dan (d) menampung tenaga kerja

Berbagai cara ditempuh pihak manajemen untuk meningkatkan volume penjualan. Mulai dari variasi produk, pemberian hadiah dan potongan harga, sampai dengan penjualan secara kredit. Perusahaan menyadari bahwa persaingan yang sangat ketat mengharuskan perusahaan untuk terus bertahan dan mampu menghasilkan laba. Tedy (2012). Masyarakat memiliki kebutuhan yang semakin banyak akan barang kebutuhan, maka kebutuhan tersebut dapat dipenuhi melalui pembiayaan konsumen. Tingginya minat konsumen untuk membeli barang-barang kebutuhan konsumen dengan cara mengangsur atau mencicil secara berkala dengan meningkatnya tarif hidup masyarakat lapisan menengah bawah, hal ini menyebabkan banyak bermunculan perusahaan-perusahaan seperti leasing. Sewa guna usaha (leasing) adalah salah satu jenis lembaga pembiayaan. Lembaga pembiayaan adalah badan usaha yang melakukan kegiatan pembiayaan dalam bentuk penyediaan dana atau barang modal. Leasing merupakan pranata hukum yang baru. Disatu pihak leasing mirip sewa menyewa, tetapi dilain pihak leasing juga mengandung unsur-unsur jual beli. Nasihin (2012:22).

Lembaga leasing merupakan alternatif yang menarik bagi para pengusaha karena saat ini mereka cenderung menggunakan dana rupiah tunai untuk kegiatan operasional perusahaan. Disamping hal tersebut di atas para pengusaha juga memperoleh keuntungankeuntungan lainnya seperti kemudahan dalam pengurusan, dan adanya hak opsi. Dalam hal ini penjualan perusahaan adalah pemberian kredit, sehingga PT. Astra Sedaya Finance di Manado memiliki piutang. Oleh sebab itu perlu adanya penerapan akuntansi piutang leasing yang sesuai dengan PSAK No.30 tentang sewa guna usaha (leasing).

\section{TINJAUAN PUSTAKA}

\subsection{Laporan Keuangan}

Menurut PSAK No. 1 (2015: 1), "Laporan keuangan adalah penyajian terstruktur dari posisi keuangan dan kinerja keuangan suatu entitas". Laporan ini menampilkan sejarah entitas yang dikuantifikasi dalam nilai moneter.

Menurut Pernyataan Standar Akuntansi Keuangan (PSAK) No. 1 paragraf 08, 09, 10, 11 dan 12 (IAI, 2015) laporan keuangan yang lengkap terdiri dari:

a) Laporan posisi keuangan pada akhir periode;

b) Laporan laba rugi komprehensif selama periode;

c) Laporan perubahan ekuitas selama periode;

d) Laporan arus kas selama periode;

e) Catatan atas laporan keuangan, berisi ringkasan kebijakan akuntansi penting dan informasi penjelasan lainnya; dan

f) Laporan posisi keuangan pada awal periode komparatif yang disajikan ketika entitas menerapkan suatu kebijakan akuntansi secara retrospektif atau membuat penyajian kembali pos-pos laporan keuangan, atau ketika entitas mereklasifikasi pos-pos dalam laporan keuangannya.

\subsection{Tujuan Laporan Keuangan}

Akuntansi keuangan berhubungan dengan masalah pencatatan transaksi untuk suatu perusahaan atau organisasi dan penyusunan berbagai laporan berkala dari hasil pencatatan. Pontoh (2013: 2). Sedangkan dalam Standar Akuntansi Keuangan dijelaskan tentang tujuan laporan keuangan yang isinya tujuan laporan keuangan adalah menyediakan informasi yang menyangkut posisi keuangan, kinerja, serta perubahan posisi keuangan suatu perusahaan, 
yang bermanfaat bagi sejumlah besar pemakai dalam pengambilan keputusan ekonomi. (Hery 2013: 12).

\subsection{Piutang}

Menurut Pontoh (2013:287), yang dimaksud dengan piutang adalah sebuah hak tagih dari sebuah organisasi (dalam hal ini perusahaan)atas sejumlah uang tunai di masa yang akan datang yang disebabkan karena transaksi masa kini. Piutang adalah klaim uang, barang atau jasa perusahaan kepada pelanggan atau pihak-pihak lainnya. Martani, dkk (2012:193).

\subsection{Leasing}

Menurut PSAK (IAI 2015) Leasing suatu sewa guna usaha diklasifikasikan sebagai sewa pembiayaan jika sewa tersebut mengalihkan secara substansial seluruh resiko dan manfaat yang terkait dengan kepemilikan asset. Pengertian leasing sesuai dengan Peraturan Menteri Keuangan Republik Indonesia Nomor 84/PMK.012/2006, Oleh Miranda, Nasihin (2013) "Sewa guna usaha (leasing) adalah kegiatan pembiayaan dalam bentuk penyediaan barang modal baik secara sewa guna usaha dengan hak opsi (Finance Lease) maupun sewa guna usaha tanpa opsi (Operating Lease) untuk digunakan oleh Penyewa Guna Usaha (Lessee) selama jangka waktu terpenuhi berdasarkan pembayaran secara angsuran.

\subsection{Kosep Leasing}

Sesuai PSAK 30 terkait dengan akuntansi leasing maka perlakuan akuntansi untuk aset dalam sewa pembiayaan yang diklasifikasikan sebagai dimiliki untuk dijual:

1. Disajikan sebagai aset tersedia untuk dijual, jika jumlah tercatatnya terutama dapat dipulihkan melalui transaksi penjualan dari pada penggunaan lebih lanjut.

2. Diukur sebesar nilai yang lebih rendah antara jumlah tercatatnya dan nilai wajar setelah dikurangi beban penjualan aset tersebut.

3. Diungkapkan dalam laporan keuangan untuk memungkinkan evaluasi dampak keuangan adanya perubahan penggunaan aset.

Perlakuan akuntansi untuk transaksi Leasing disesuaikan dengan jenis sewanya masing-masing. Sistem Leasing ada 2 yaitu financing/capital lease dan operating lease. Perlakuan akuntansi untuk kedua sistem ini berbeda.

1. Capital Lease/Financing Lease atau Pengakuan Awal. Pada awal masa sewa, lessee mengakui sewa pembiayaan sebagai aset dan kewajiban dalam neraca sebesar nilai wajar aset sewaan atau sebesar nilai kini dari pembayaran sewa minimum, jika nilai kini lebih rendah dari nilai wajar. Penilaian ditentukan pada awal kontrak. Tingkat diskonto yang digunakan dalam perhitungan nilai kini dari pembayaran sewa minimum adalah tingkat suku bunga implisit dalam sewa, jika dapat ditentukan secara praktis; jika tidak, digunakan tingkat suku bunga pinjaman inkremental lessee. Biaya langsung awal yang dikeluarkan lessee ditambahkan ke dalam jumlah yang diakui sebagai aset. Biaya langsung awal (initial direct costs) adalah biaya-biaya tambahan (inkremental) yang terjadi yang dapat diatribusikan secara langsung dengan negosiasi dan pengaturan sewa, kecuali biaya-biaya yang dikeluarkan oleh lessor pabrikan atau lessor dealer.

Tingkat bunga pinjaman inkremental lessee (lessee's incremental borrowing rate of interest) adalah tingkat bunga yang harus dibayar lessee dalam sewa yang serupa atau, jika tingkat bunga tersebut tidak dapat ditentukan, tingkat bunga yang pada awal sewa yang harus ditanggung oleh lessee ketika meminjam dana yang diperlukan untuk membeli aset tersebut yang mana pinjaman ini mencakup periode dan jaminan yang serupa. Pada saat pengakuan awal, kita mengakui aset dan kewajibannya, yaitu Aset sewa guna usaha = Hutang sewa guna usaha sehingga jurnalnya bisa dicatat sbb:

Aset sewa guna usaha $\mathrm{XXX}$

Hutang sewa guna usaha XXX 
Pengukuran setelah pengakuan awal pembayaran sewa minimum harus dipisahkan antara bagian yang merupakan beban keuangan dan bagian yang merupakan pelunasan kewajiban. Beban keuangan harus dialokasikan ke setiap periode selama masa sewa sedemikian rupa sehingga menghasilkan suatu tingkat suku bunga periodik yang konstan atas saldo kewajiban. Jurnal yang dicatat adalah:

Beban Bunga

XXX

Hutang sewa guna usaha $\quad \mathrm{xxx}$

kas $\quad \mathrm{xxx}$

Ayat jurnal untuk mencatat pengakuan penyusutan aset:

Beban penyusutan aset lease $\quad \mathrm{xxx}$

Akumulasi penyusutan aset lease $\quad \mathrm{xxx}$

2. Operating Lease. Pembayaran sewa dalam sewa operasi diakui sebagai beban dengan dasar garis lurus (straight-line basis) selama masa sewa kecuali terdapat dasar sistematis lain yang dapat lebih mencerminkan pola waktu dari manfaat aset yang dinikmati pengguna. Sewa operasi, pembayaran sewa (tidak termasuk biaya jasa seperti biaya asuransi.dan pemeliharaan) diakui sebagai beban dengan dasar garis lurus kecuali terdapat dasar sistematis lain yang lebih mencerminkan pola waktu dari manfaat yang dinikmati pengguna, walaupun pembayaran dilakukan tidak atas dasar tersebut.

Leasing tipe ini, tidak terjadi transfer kepemilikan aset dan hanya dianggap menyewa saja sehingga pembayarannya langsung dibebankan pada laporan keuangan. Menurut prinsip dasar akuntansi bahwa, $($ Aset $=$ Hutang + Modal $($ Laba Ditahan Awal + Pendapatan - Laba Ditahan Akhir)

Pada saat pembayaran leasing tersebut akan berpengaruh sbb :

Beban Sewa

XXX

Kas

XXX

Kas merupakan aset, karena ada pembayaran kas jadi berkurang, beban sewa langsung berpengaruh terhadap net income sehingga mengurangi pendapatan dan akibatnya mengurangi equity (modal).

\section{Pelaporan Leasing}

Finance leasse - lessor

1. Aktiva dilaporkan berdasarkan urutan likuiditasnya, kewajiban diurutkan berdasarkan jatuh temponya tanpa mengelompokkan kedalam unsur lancar dan tidak lancar.

2. Penanaman neto dalam aktiva yang disewagunausahakan harus dilaporkan dalam neraca dengan rincian sebagai berikut:

Piutang sewa guna usaha $\quad$ xxx

Nilai sisa yang terjamin $\quad \mathrm{xxx}$

Pendapatan sewa guna usaha yang belum diakui $\quad \mathrm{xxx}$

Simpanan jaminan $\quad$ Xxx

Penanaman neto sewa guna usaha $\quad \mathrm{xxx}$

Penyisihan piutang sewa guna usaha yang diragukan $\mathrm{xxx}$

Jumlah penanaman neto $\quad \mathrm{xxx}$

3. Laporan laba rugi disajikan sedemikian rupa sehingga seluruh pendapatan dilaporkan dalam kelompok yang terpisah dari kelompok biaya.

4. Jumlah penanaman neto dan pendapatan sewa guna usaha dalam sewa guna usaha sindikasi dan leveraged leasees harus dilaporkan oleh masing-masing pihak secara proporsional sesuaii dengan penyertaanya 


\section{Operating lease - lessor}

1. Barang modal yang disewa guna usahakan dilaporkan berdasarkan harga perolehan setelah dikuirangi akumulasi penyusutannya.

2. Aktiva yang disewa guna usahakan dilaporkan secara terpisah dari aktiva tetap yang tidak disewa guna usahakan.

3. Perhitungan rugi laba harus disusun sedemikian rupa sehingga seluruh pendapatan dilaporkan dalam kelompok yang terpisah dari kelompok biaya.

4. Penyusutan aktiva yang disewa guna usaha harus dilaporkan secara terpisah dari aktiva yang tidak disewa guna usahakan.

\subsection{Penelitian Terdahulu}

1. Penelitian yang dilakukan Runtuwene (2013) Perusahaan menerapkan model akuntansi leasing capital lease lebih tepatnya model direct financing lease atau metode pembiayaan langsung.

2. Penelitian yang dilakukan Sumual (2013) hasil penelitiannya menunjukkan pencatatan transaksi pada PT Astra Seaya Finance menggunakan metode direct financing lease

3. Penelitian yang dilakukan Nur (2013) Berdasarkan kriteria klasifikasi sewa guna usaha, perusahaan melakukan transaksi sewa pembiayaan

\section{METODE PENELITIAN}

\subsection{Jenis dan Sumber Data}

Jenis penelitian dalam penelitian ini adalah penelitian deskriptif, yaitu dengan cara mengumpulkan, mengklasifikasikan, menganalisis, dan menginterprestasikan data-data yang telah diambil pada perusahaan secara lisan maupun tulisan. Sumber data yang digunakan dalam penelitian ini yaitu sebagai berikut:

1. Data Primer, berupa data yang diperoleh secara langsung dari perusahaan melalui wawancara dengan kepala bagian piutang, dan karyawan yang terkait langsung dengan objek yang diteliti, dan kegiatan observasi.

2. Data Sekunder, berupa data yang dikumpulkan melalui catatan dan dokumen resmi perusahaan dan data yang telah diolah seperti sejarah singkat perusahaan, struktur organisasi, dan dokumen lainnya.

\subsection{Metode Analisis Data}

Metode analisis data yang dilakukan dalam penelitian ini adalah metode deskriptif, yaitu dengan terlebih dahulu mengumpulkan data yang ada kemudian diklarifikasi, dianalisis selanjutnya di interprestasikan sehingga dapat memberikan gambaran yang jelas mengenai keadaan yang diteliti.

\section{HASIL ANALISIS DAN PEMBAHASAN}

\subsection{Hasil Analisis}

\subsubsection{Proses Terjadinya Piutang Leasing}

Setelah adanya kesepakatan antara pihak perusahaan dengan pihak pembeli, yang dimana sebelumnya sudah diadakan survei terhadap calon konsumen dan sudah diautorisasi, maka selanjutnya perusahaan dan calon konsumen menandatangani surat perjanjian kontrak. Piutang dianggap sudah terjadi.

\subsubsection{Pengakuan dan Pencatatan Piutang Leasing}

Dalam pengakuan dan pencatatan PT. Astra Sedaya Finance di Manado menggunakan model akuntansi leasing financial lease, lebih tepatnya model pembiayaan langsung. Di dalam melaksanakan transaksi leasing PT. Astra Sedaya Finance di Manado mencatat setiap transaksi penjualan kendaraan sebagai berikut : 


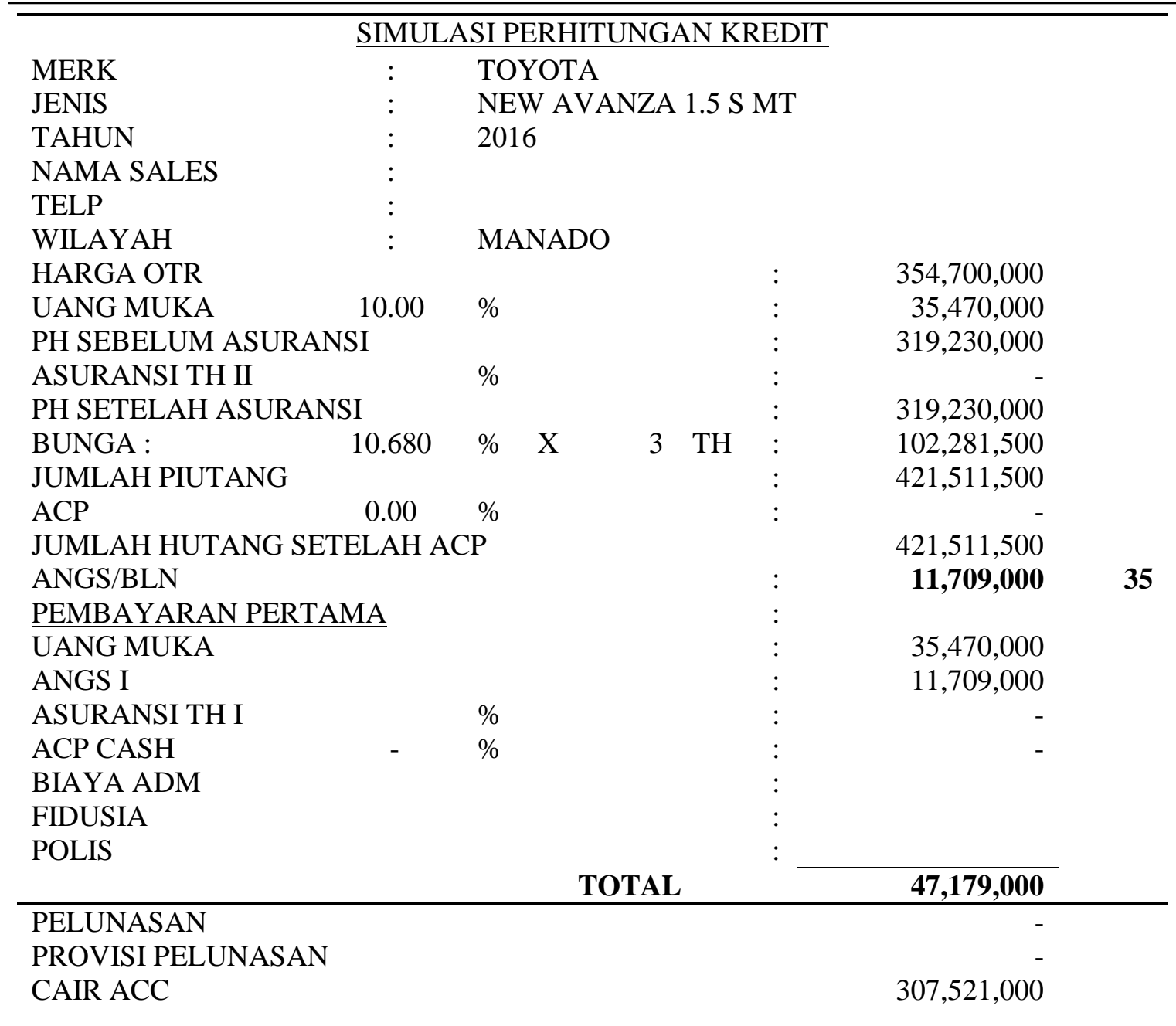

Contoh untuk mencatat lease :

Piutang lease

Aktiva

Pendapatan bunga diterima dimuka

Piutang lease
$421,511,500$

$319,230,000$

$102,281,500$

$47,179,000$

Contoh untuk mencatat pada saat pembayaran angsuran per bulan : Kas

$11,709,000$

Piutang lease

$11,709,000$

Contoh untuk mencatat pengakuan bunga yang diperoleh per bulan :

Pendapatan bunga diterima dimuka $\quad 2,841,153$

Pendapatan bunga 2,841,153

\subsubsection{Pelaporan dan Pengungkapan}

Hasil akhir dari proses akuntansi keuangan adalah penyajian laporan keuangan yang terdiri dari perhitungan rugi laba, neraca dan laporan arus kas. Laporan keuangan tersebut disajikan setiap tahun agar dapat dinilai oleh pihak yang memerlukan. Laporan keuangan dibuat sebaik-baiknya untuk memberikan informasi yang akurat dalam pengambilan keputusan perusahaan maupun pengguna lainnya. 
PT. Astra Sedaya Finance melaporkan neraca sebagai berikut, contoh laporan Tahun 2016 (dalam miliaran rupiah, kecuali dinyatakan lain :

\section{ASSET}

Kas dan setara kas

- Pihak ketiga

- Pihak berelasi

Piutang pembiayaan konsumen setelah dikurangi penyisihan kerugian penurunan nilai

- Pihak ketiga

- Pihak bereliasi

Piutang pembiayaan Murabahah setelah dikurangi penyisihan kerugian penurunan nilai

- Pihak ketiga

Investasi bersih dalam sewa pembiayaan setelah dikurangi penyisihan kerugian penurunan nilai

- Pihak ketiga

- Pihak berelasi

Beban dibayar dimuka

- Pihak ketiga

- Pihak berelasi

Piutang lain-lain

- Pihak ketiga

- Pihak berelasi

Asset derivatif

Asset pajak tangguhan bersih

\section{LIABILITAS}

LIABILITAS DAN EKUITAS

Utang penyalur kendaraan

- Pihak ketiga

- Pihak berelasi

Utang lain-lain

- Pihak ketiga

- Pihak berelasi

Akrual

- Pihak ketiga

Liabilitas pajak

- Pajak penghasilan badan

- Pajak lainnya

Liabilitas derivatif

Pinjaman

- Pihak ketiga

Surat berharga yang diterbitkan

- Obligasi

- Imbalan kerja 
Agio saham

Saldo Laba

- Telah ditentukan penggunanya

- Belum ditentukan penggunanya

Cadangan linding nilai arus kas

\subsection{Pembahasan}

Dari hasil pembahasan PT. Astra Sedaya Finance Manado menggunakan model akuntansi leasing Financial lease. Dalam hal ini penerapan akuntansi piutang oleh PT.Astra Sedaya Finance Manado telah sesuai dengan PSAK NO.30 tentang sewa. Contohnya penerapan akuntansi sewa pembiayaan langsung. Lessor dalam sewa pembiayaan langsung membeli aktiva untuk memenuhi kebutuhan transaksi leasing dan segera menyewakan aktiva tersebut kepada penyewa. Aktiva yang dibeli itu hanya sebentar dalam pembukuan lessor. Secara konseptual, akuntansi untuk sewa pembiayaan langsung identik dengan akuntansi untuk pelepasan aktiva secara kredit. Namun lessor tidak melaporkan piutang usaha melainkan melaporkan piutang sewa di neraca. Lessor tidak melakukan penyusutan aktiva, dan laba lessor seluruhnya berasal dari bunga. Dilihat juga dari perbandingan laporan antara perusahaan dan psak No.30 berikut :

Tabel 4.1 Perbandingan pelaporan antara PT. Astra Sedaya Finance dengan teori PSAK 30

\begin{tabular}{|c|c|c|c|c|}
\hline No & KET & Dasar Teori & Perusahaan & Kesimpulan \\
\hline 1 & $\begin{array}{l}\text { Financial/ } \\
\text { Capital } \\
\text { lease }\end{array}$ & $\begin{array}{lr}\text { Aktiva } & \text { dilaporkan } \\
\text { berdasarkan } & \text { urutan } \\
\text { likuiditasnya, } & \text { kewajiban } \\
\text { diurutkan berdasarkan jatuh } & \text { tanpa } \\
\text { temponya } & \text { tankelam } \\
\text { mengelompokkan } & \text { kedalam } \\
\text { unsur lancar dan tidak lancar }\end{array}$ & $\begin{array}{lr}\text { Perusahaan } & \\
\text { melaporkan } & \\
\text { semuanya } & \text { secara } \\
\text { menyeluruh } & \text { dan } \\
\text { tidak di } & \text { pisah- } \\
\text { pisahkan } & \end{array}$ & $\begin{array}{l}\text { Pelaporan PT.ASF } \\
\text { sesuai dengan teori } \\
\text { yang ada }\end{array}$ \\
\hline 2 & $\begin{array}{l}\text { Financial/ } \\
\text { Capital } \\
\text { lease }\end{array}$ & \begin{tabular}{lr}
\multicolumn{2}{l}{ Penanaman neto dalam aktiva } \\
yang & disewagunausahakan \\
harus & dilaporkan dalam \\
neraca &
\end{tabular} & $\begin{array}{l}\text { Perusahaan } \text { selalu } \\
\text { melaporkan seluruh } \\
\text { aktiva dalam neraca } \\
\text { per tahunnya }\end{array}$ & $\begin{array}{l}\text { Pelaporan PT.ASF } \\
\text { sesuai dengan teori } \\
\text { yang ada }\end{array}$ \\
\hline 3 & $\begin{array}{l}\text { Financial/ } \\
\text { Capital } \\
\text { lease }\end{array}$ & $\begin{array}{l}\text { Laporan laba rugi disajikan } \\
\text { sedemikian rupa sehingga } \\
\text { seluruh } \\
\text { dilaporkan dalam kelompok } \\
\text { yang terpisah dari kelompok } \\
\text { biaya }\end{array}$ & $\begin{array}{l}\text { Dalam laporan } \\
\text { perusahaan, } \\
\text { perusahaan } \\
\text { melaporkan antara } \\
\text { neraca, laba rugi } \\
\text { maupun laporan arus } \\
\text { kas secara terpisah } \\
\end{array}$ & $\begin{array}{l}\text { Pelaporan PT.ASF } \\
\text { sesuai dengan teori } \\
\text { yang ada }\end{array}$ \\
\hline 4 & $\begin{array}{l}\text { Financial/ } \\
\text { Capital } \\
\text { lease }\end{array}$ & $\begin{array}{l}\text { Jumlah penanaman neto dan } \\
\text { pendapatan sewa guna usaha } \\
\text { dalam sewa guna usaha } \\
\text { sindikasi dan leveraged } \\
\text { leasees harus dilaporkan oleh } \\
\text { masing-masing pihak secara } \\
\text { proporsional sesuai dengan } \\
\text { penyertaannya }\end{array}$ & $\begin{array}{lr}\text { Seluruh } & \text { laporan } \\
\text { dalam perusahaan } \\
\text { mengenai } \\
\text { sewagunausaha } \\
\text { selalu dilaporkan } \\
\text { dengan tepat } \\
\text { disertakan dengan } \\
\text { bukti yang ada } \\
\end{array}$ & $\begin{array}{l}\text { Pelaporan PT.ASF } \\
\text { sesuai dengan teori } \\
\text { yang ada }\end{array}$ \\
\hline
\end{tabular}




\section{KESIMPULAN DAN SARAN}

\subsection{Kesimpulan}

Berdasarkan penelitian dan pembahasan maka dapat disimpulkan perlakuan akuntansi leasing dan pelaporan pada PT. Astra Sedaya Finance di Manado cukup baik. Dilihat dari hasil penelitian :

1. Penerapan akuntansi PT. ASTRA SEDAYA FINANCE Manado menggunakan model akuntansi Financial lease dengan metode pembiayaan langsung.

2. Berdasarkan aspek pengakuan dan pencatatan, diakhir periode lease diakui adanya pengalihan kepemilikan, menunjukkan sistem financial lease diberlakukan dalam sistem akuntansi PT. Astra Sedaya Finance

3. Berdasarkan aspek pelaporan akuntansi leasing pada PT Astra Sedaya Finance dicatat sesuai dengan PSAK yang berlaku

4. Berdasarkan aspek pengungkapan catatan atas laporan keuangan PT. Astra Sedaya Finance telah membuat catatan atas laporan keuangan sudah sesuai dengan standar yang ditentukan

\subsection{Saran}

Berdasarkan hasil pembahasan dalam penelitian ini, adapun saran yang dapat penulis kemukakan sebagai berikut:

1. PT. Astra Sedaya Finance di Manado sebaiknya melakukan pemisahan pencatatan penyusutan aktiva tetap dengan aktiva yang disewagunakan.

2. PT. Astra Sedaya Finance di Manado sebaiknya selalu mengikuti perkembangan peraturan pelaporan yang terkait dengan transaksi leasing, sehingga tidak menimbulkan banyak perbedaan antara perlakuan akuntansi dengan menggunakan metode pencatatan perusahaan.

\section{DAFTAR PUSTAKA}

Albertus. 2013. Prinsip-prinsip dasar akuntansi. Dunia Cerdas. Jakarta

Astra Credit Companies. Syarat mengajukan kredit. https://www.cermati.com/kredit-mobilbekas/astra-credit-companies-kredit-mobil-

bekas?price $=100000000 \&$ downPayment $=30000000 \&$ insuranceType $=$ all $\&$ area $=$ SULA

WESI+UTARA\&year $=2017 \&$ tenure $=24 \#$ focus-simulation

Hanafi. 2015. Analisis laporan keuangan. Yogyakarta: (UPP) STIM YKPN

Hery, 2013. Analisis Laporan Keuangan. Penerbit PT Gramedia Widiasarana Indonesia.

Jakarta

Ikatan Akuntan Indonesia (IAI). Standar Akuntansi Keuangan (SAK) perefektif 1 Januari 2015

Kasmir. 2013. Analisis laporan keuangan. Rajawali Pers, Jakarta

Martani, Dwi, Sylvia Veronica NPS, dkk. 2012. Akuntansi keuangan menengah berbasis PSAK. Salemba Empat, Jakarta

Nasihin, Miranda. 2012. Segala hal tentang hukum lembaga pembiayaan. Penerbit: Buku Pintar, Yogyakarta

Nur. 2014. Analisis Akuntansi Sewa Berdasarkan PSAK No.30. Tanggal Akses 20 Januari 2017.http://jurnal.umrah.ac.id/wp-content/uploads/gravity_forms/1ec61c9cb232a03a96d0947c6478e525e/2014/09/JURNAL-NURIZATI 100462201165.pdf

Pontoh Winston. 2013. Akuntansi konsep dan praktik. Penerbitan Halaman Moeka. Jakarta Barat.

Runtuwene Irene Herminda. 2013. Penerapan Akuntansi Piutang Leasing Untuk Perencanaan Dan Pengungkapan Pada PT. Suzuki Finance Indonesia cabang manado. Fakultas 
Ekonomi Dan Bisnis Universitas Sam Ratulangi. Jurnal Ekonomi Manajemen Bisnis Akuntansi. Vol 1 No 4 Desember 2013. Diakses Mei 2017

Sumual Micky. 2015. Analisis Perlakuan Akuntansi Leasing Dan Pelaporan Nya Pada PT.Astra Sedaya Finance. Fakultas Ekonomi Dan Bisnis Universitas Sam Ratulangi. Jurnal Ekonomi Manajemen Bisnis Akuntansi. Diakses Mei 2017.

Tedy, 2012. Tujuan Perusahaan, http://tedihyo.blogspot.co.id/2012/03/tujuanperusahaan.html?m=1. Di Unduh Juli 2017 